\title{
An Interdisciplinary Approach to the Design and Implementation of a University-oriented Internal Communications Strategy for a Bachelor of General Studies Degree Program
}

\author{
Devon Cadwell Bazata ${ }^{*}$, Thomas D. Cox ${ }^{2}$, David N. Boote ${ }^{3}$ \\ ${ }^{1}$ College of Undergraduate Studies, University of Central Florida \\ ${ }^{2}$ College of Community Innovation and Education, University of Central Florida \\ ${ }^{3}$ Learning Sciences and Educational Research, University of Central Florida \\ Email: Devon.CadwellBazata@ucf.edu
}

\begin{abstract}
Leading an interdisciplinary program change is challenging. Effectively communicating those changes across a University brings additional challenges associated with organizational and cultural differences across administrative and academic units. This design-based research study used exploratory sequential mixed methods to develop a strategic internal communication plan for a new Bachelor of General Studies degree. Data included interviews with four university administrators and faculty who were involved in the development of the BGS degree program followed by a survey completed by 161 staff and faculty advisors and administrators outside of the program. Interview and survey results were interpreted using sociocultural learning, co-orientation theory, and a two-way symmetrical model of communication. Findings emphasize the importance of cultural differences across administrative and academic units: collectivism (community), professionalism (cooperation and trust), balanced power-distance (student-centered learning balanced with the expertise and authority of the faculty), pragmatism (practical results and blunt pragmatic communication style), and a results-oriented approach. The results were used to design an internal marketing plan that promotes sociocultural learning across cultural differences within the university and reciprocal exchange of information among undergraduate faculty and advisors.
\end{abstract}

Keywords: higher education, organizational culture, communication, general studies, sociocultural learning

\section{Introduction}

The purpose of this study was to identify dimensions of organizational culture (Hofstede et al., 1990) from interview results of university-level administrators and faculty involved in the development of the BGS degree program, to develop a survey based on those results and administered to undergraduate faculty and academic advisors, and to utilize those results along with communication theory in order to develop to a strategic internal communication plan to promote common ground and collaborative efforts in an institution historically organized along disciplinary lines (Brewer, 1999). Key stakeholders were defined as those who the BGS degree program impacted: undergraduate faculty and advisors, university administrators, faculty, staff with direct BGS program responsibility, and the intended beneficiaries of the program, including students, their families, their current or potential employers or graduate programs.

Communication reinforces the cultural identity of the organization and all that it values. For the present study, culture is understood to be "the collective programming of the mind that distinguishes the members of one group or category of people from others" (Hofstede, 1984, p. 51), and includes the day-to-day patterns or ways of living that define one group from another (Damen, 1987). The characteristics of organizational culture are related to the ways things have historically been done, are socially constructed, and are usually hard to change (Hofstede et al., 1990). Culture includes deeper-level values and the behaviors, attitudes, knowledge specific to an institution, and often between groups within that institution.

The organizational culture of the university is a variable closely associated with both employee communication and internal public relation strategies (Smircich, 1983; Sriramesh et al., 1992). Employee communication is the way information is communicated within the organization, is a sub-discipline of communication, and is a practice area of internal public relations (Grunig et al., 2002). Employee communication has two components: communication content and communication climate (Smidts, et al., 2001), both of which are influenced by organizational culture (Sriramesh et al., 1992, Rhee \& Moon, 2009).

To gain a better understanding of the organizational culture of the undergraduate advising community, the author used an exploratory sequential design (Creswell, 2008). In the qualitative study, interviews were conducted with a sample size of four, and in the quantitative study, surveys were distributed to all of the university's 2059 full-time faculty and academic 
advisors. Of that number, there were 338 total filtered response counts, a $16.4 \%$ response rate, with 197 or $58.2 \%$ out of the 338 responding that they advised undergraduate students. Of that 197,161 or $47.5 \%$ completed the anonymous survey. The qualitative results provided an orientation of the complex problem, solution, and dimensions of culture involved in the development of the degree program. The analysis of the qualitative results was done using thematic content analysis (Braun \& Clarke, 2006; Guest et al., 2012) and interpreted using program theory (Chen, 1990) and a logic model. The analysis of the quantitative results was done using SPSS data analysis software.

The results from the interviews and surveys were integrated with communication theory, education and sociocultural learning, and social psychology's dimensions of culture to create a strategic internal communication plan. The process was not linear, but used systems thinking and systems mapping to deconstruct the complex problem and understand it as a system. Systems thinking was useful to map the problem in order to understand how the constituent parts of the problem related to each other and to the problem as a whole (Repko \& Szostak, 2017; Szostak, 2004).

\section{Studies}

\subsection{Study 1: Qualitative interviews}

The purpose of the interviews was to gather data from administrators and faculty about their perceptions and beliefs related to the BGS degree program.

Although the qualitative research portion of this study was not phenomenological, per se, it did involve the phenomenon of university administrators who were living through and experiencing the problem of the "gates" within university degree programs, with the term "gates" being representative of the requirements students must meet in order to be admitted to or graduate from a degree program. For example, the capstone course in the mechanical engineering program is a gate that leads to program completion, one that requires students to earn a $\mathrm{C}$ or better in order to graduate. Students who do not pass this type of final course are unable to graduate. Another example of a gate is the pre-requisites required for admission to a degree program. Students who have changed majors may be unable to complete the pre-requisites required for program admission and may continue to accumulate undergraduate credit hours in excess of the 120 required to graduate from most degree programs. The pre-requisites are a gate that does not allow students into a degree program and leaves them without a pathway to graduation.

While the BGS program was designed to provide students a pathway to graduation, it was also designed to address and support the university and its stakeholders' structural, political, and symbolic interests. The interviews provided insight to the structural causes of the problem and included degree programs students were disqualified from, unable to be admitted to, or conversely, were unable to pass the final coursework requirements. Political causes were related to the increasing number of students accepted through alliances formed with partner state college programs, continuing education, the university's global program that teaches international students English and prepares them to apply to the university as matriculated students, and the university's online degree programs. The symbolic causes and perspectives included beliefs and perceptions of undergraduate faculty and advisors about university priorities, standards of rigor associated in disciplinary vs. general studies degrees, the attitudes and beliefs about the university as a closed vs. open system, and the university's practices. These three organizational theory lenses were used first to develop the interview questions for the small group of four administrators and faculty involved with the development of the BGS degree program, and second for the survey questions for the undergraduate faculty and academic advisors. The interview questions were aligned with dimensions of both national and organizational culture. Hofstede's (1984) dimensions of national culture examined were individualism vs. collectivism, and power distance. Hofstede's (2011) dimensions of organizational culture examined were professional vs. parochial, process-oriented vs. results-oriented, and pragmatic vs. normative.

Methods of Study 1 are as follows.

\subsubsection{Research question}

RQ1. What is the organizational culture of the university administrators and faculty

member who were interviewed?

\subsubsection{Sample}

Interviews were conducted with three university administrators and one faculty member familiar with the BGS initiative. All participants gave verbal consent for the interview to be recorded and acknowledged that they could stop or leave the interview at any time. 


\subsubsection{Interview protocol}

Interviews were conducted to understand the future the four key stakeholders envisioned for the BGS program and to identify dimensions of culture. Participants were asked for professional information about themselves and questions (Appendix A) based on their structural perspective of how the BGS degree would fit within the structure of the university, the short, medium, and long-term program outcomes in the areas of learning (awareness/knowledge of the program within the university, attitudes toward it, skills associated with it, motivations - university and student); action (anticipated behavior of stakeholders, practice [whether stakeholders would refer students to the program], and policies); and conditions (social and economic conditions that contributed to the problem and how BGS is expected to benefit stakeholders).

All interviews were conducted on the university campus, with two conducted in the interviewees' offices, and two conducted in the author's office. Interviews were recorded using the iOS Voice Memo app, and notes were taken during each interview. The recordings were transcribed verbatim using computer-based artificial intelligence technology offered in the Transcribe - Speech to Text app, and the transcriptions were reviewed and edited while listening twice to the audio recording of each interview.

The transcriptions were coded and evaluated for themes and patterns and data were analyzed using thematic content analysis (Braun \& Clarke, 2006; Guest et al., 2012) with program theory as the theoretical framework. The process of organizing the data began with identifying significant statements from each interview, and then creating formulated meanings from these significant statements. Formulated meanings were organized into clusters of themes, followed by the emergent themes. Examples from this process are provided in Tables 1 and 2.

\subsection{Study 2: Survey of faculty and academic advisors}

The questions in this nonexperimental research design survey were written to provide data about undergraduate faculty and academic advisors' knowledge, perceptions and beliefs about the complex problem, university priorities, and core metrics, and dimensions of culture identified in the interviews. Survey responses were evaluated to identify statistically significant differences between undergraduate faculty and academic advisor, and compared to interview results.

Methods of Study 2 are as follows.

\subsubsection{Research questions}

RQ2. Are faculty or academic advisors who advise students formally or informally more likely to suggest to an undergraduate student that they change degree programs to Interdisciplinary Studies?

RQ3. Are faculty and academic advisors more likely to have heard about the newly created BGS degree?

RQ4. What is the likelihood that faculty or academic advisors will suggest to an undergraduate that they change degree programs to BGS?

RQ5. Does the organizational culture of the undergraduate faculty and academic advisors who were surveyed differ from the dimensions of culture of the university administrators and faculty member interviewed?

\subsubsection{Instrument}

To collect the data, the author developed the Bachelor of Integrative General Studies online anonymous survey in Fall, 2019. The survey was pilot-tested with two faculty members and revisions were made in response to the feedback and suggestions they provided. There was one initial filter question, and nine survey questions in total. The questions were based on two different instruments, the Higher Education Research Institute (HERI) Faculty Survey Instrument (2016-2017) provided the basis for the first five and last three knowledge-based questions adapted for the purpose of this survey, plus the initial filter question, "Do you advise undergraduate students?" Ten different statements comprised question six with responses in a four-point Likert scale with a forced choice (Allen \& Seaman, 2007) from strongly agree, agree, disagree, and strongly disagree. The first, and fourth through seventh statements in this question were based on Hofstede's (2011) work Dimensionalizing Cultures: The Hofstede Model in Context. The second, third, and eighth through tenth questions were based on metrics in the university's Collective Impact Plan (2017). The survey was anonymous, meaning that no individually identifiable information was collected. In any reports that used data, it was only reported after it was combined with other participant's responses. This information will be retained for a period of five years, and is stored within a password protected account in the university's Qualtrics survey system through which the data and reports were generated.

\subsubsection{Participants}

Survey participants were full-time faculty and academic advisors who worked at the university for at least nine months of the year. Their participation in the study was voluntary, and they were free to withdraw their consent and discontinue participation in this study at any time without prejudice or penalty. It was stated clearly in the Explanation of Research 
invitation to participate that their decision to participate or not participate in this study would in no way affect their relationship with the university, including continued enrollment, grades, employment, or relationship with the individuals who may have an interest in this study.

Participants had to be at least 18 years of age or older to take part in the research study. The study's inclusion/exclusion criteria stated that individuals who were employed full-time as faculty or academic advisors were eligible for inclusion in this study. Individuals employed part-time as faculty or academic advisors were excluded. To have participated in this study, participants had to meet the requirements of both the inclusion and exclusion criteria.

\subsubsection{Procedure}

The list of participants for the survey was generated by the university's Institutional Knowledge Management (IKM) unit and emailed to the author on November 27, 2019 in response to the data request "IKM-505 Contact List of Full-Time Faculty and Advisors." The data provided by IKM was from the university's PeopleSoft database, and based on data pulled on November 15, 2019. The list included 9-month and 12-month faculty as well as all academic advisors. Full-time was defined as anyone working at or above a 0.75 FTE. The term "FTE" refers to the number of hours the employee is contracted for out of a 40-hour work week, with 20 hours being .50 FTE, and 40 hours being 1.0 FTE. The list included names, job titles, email addresses, as well as college and home department names. Those missing a college name were working in nonacademic units.

Since the survey was anonymous, the columns with personally identifiable information were deleted from the distribution list and the remaining list of e-mails was uploaded to the Qualtrics Contacts tab to create a contact list. The survey was distributed to all 2062 participants on the distribution list three times. The first distribution was on December 4, 2019, the first day of the final exam period, the first semester that BGS was offered. The second distribution was on December 16, 2019, the day that grades were due from faculty to the university Registrar. The third and final distribution was on January 6, 2020, the first day of the Spring 2020 semester. The survey was closed at 12 noon on January 9, 2020. Three e-mails were returned undelivered after each mailing, and 2059 e-mails were delivered. Of that number, there were 338 total filtered response counts: 334 participants responded "Yes" to giving consent to participate, two responded "No", and two participants opened and left the survey open at least 24 hours before it closed. The number responses was 338/2059, or $16.4 \%$. In the second filter question, "Do you advise undergraduate students?" The total number of participants who responded "Yes," they advise students was 197 , or, $58.2 \%$ out of the 338 . Of that 197,161 or $47.5 \%$ completed the survey. It is not possible to say what proportion of the total population this sample represents because there is no accurate count of the number of faculty and advisors who advise undergraduate students.

Participants completed the 5-minute web-based online Qualtrics survey. The consent letter informed them that the survey was anonymous and that only the researcher and dissertation chair would have access to the results.

\subsubsection{Validity}

Limited evidence for the validity of the scores is provided by the fact that established instruments used in the HERI Faculty Survey (2013), Hofstede, Neuijen, Ohayv, and Sanders (1990), and Hofstede (1980, p. 326-331) organizational culture instruments have been previously reported in the literature.

\section{Study results and summaries}

\subsection{Study 1}

\subsubsection{Results}

The two main themes that emerged were a) student motivations (who these students are, and their primary reason for changing their degree to BGS); b) university motivations for the BGS degree (both the perceptions of the degree and impact). The interviewees believed that decreased time to graduation would be students' primary motivation, and an increase in completion rates and an increase in the number of students who graduate within four years, or six years were university motivations. The main points in the interview results were as follows.

(1) Students unable to graduate from or gain entry to their chosen degree program were accumulating excess credit hours over the 120 required for a bachelor's degree. The three administrators had more experience with and understanding of this complex problem than the faculty. The faculty member was more aware of the personal, financial, and professional issues this problem caused for students, while the administrators were aware of the ways it impacted the university and key performance metrics associated with funding. Survey questions developed from this point measured faculty and academic advisors' knowledge about the percentage of students with 120 or more credit hours but unable to graduate. This related 
to who is responsible for addressing this problem, and whether the purpose of education was viewed as how to learn (individualism), or how to do (collectivism) (Hofstede, 2011).

(2) Different types of students earn university degrees for different reasons. Identifying students who are a good fit for the BGS program was related to the reasons why a student was earning the degree. Survey questions developed from this point were based on perceptions about whether undergraduate students with more than 120 credit hours should be eligible to earn an undergraduate degree; if degree programs that prepare students to solve today's complex problems was a university priority; and if there was a perceived difference in the university's priority of graduation rates for different types of students including first time in college (FTIC) students, transfer students, and non-traditional students. These main points all related to the State University System's 2025 Strategic Plan (State University System of Florida, 2019) and the core metrics related to state funding. Also present in this data were the parochial vs. professional cultural dimensions (Hofstede et al., 1990). If the dimension of culture were parochial, then faculty and advisors would find it difficult to accept anything different than the traditional disciplinary silos that define the structure of the university. A professional dimension would be more open to working collaboratively (Hofstede, Neuijen et al., 1990). Other dimensions of culture reflected were pragmatic vs. normative (Hofstede, 1998), where a pragmatic organization values results more than normative procedures; and a process-oriented vs results-oriented culture (Hofstede, 2011), where a results-oriented culture accepts unfamiliar situations and demonstrates a strong concern for outcomes.

(3) Leaving a degree program does not mean a student has left behind the knowledge gained in coursework or no longer belongs at the university. Students who leave a degree program, either voluntarily or due to GPA requirements or other reasons, rely on their faculty advisor or academic advisor to direct them to other options. Survey questions developed from this point asked whether faculty and advisors had ever suggested a student change degree programs to IDS, and how likely it would be they would suggest a student change degree programs to BGS. Also developed from this point were statements to evaluate perceptions about power distance as it related to a student-centered education vs a faculty or departmental-centered one (Hofstede, 1984).

(4) The university is motivated to step in if a student leaves a degree program and offer other degrees for students to graduate in order to help students meet their goals and to help the university meet its own goals of completion rates and time to degree. Survey questions developed from this point were based on the sense of community, (individualism vs. collectivism) both within degree programs and within the university, and on whether collaborative efforts between degree programs were prioritized (parochial vs. professional) (Hofstede et al., 1990).

(5) It is the university's institutional imperative to increase access to education for students, and find ways to decrease time to degree. The survey questions developed from this point were based on perceptions about the priority the university places on lowering time to degree, and whether faculty and academic advisors believed that the organizational culture was results-oriented or process-oriented (Hofstede et al., 1990).

\subsubsection{Summary}

The results of the interviews provided the answer to RQ1:

RQ1. What is the organizational culture of the university administrators and faculty member who were interviewed?

Answer: The university-oriented organizational culture of the administrators and faculty was community-oriented and collectivist as opposed to individualistic; professional and open to an organizational framework that differed from the traditional disciplinary structure representative of a parochial culture; had a low power distance indicative of a studentcentered education; was pragmatic and results-oriented as represented by a willingness to be flexible and adaptive; and included the perception that undergraduate faculty and academic advisors were equally knowledgeable about the university's priorities.

\subsection{Study 2}

\subsubsection{Results}

There were 161 responses, with 128 or $79.5 \%$ from faculty, and 33 or $20.5 \%$ from advisors. These were the filtered responses of the 341 participants who took the survey, with a total of 161 who reported that they advise students, either formally or informally. Responses were divided into two groups: Faculty and Academic Advisors. The data were analyzed using SPSS data analysis software.

The first question asked if the participant had ever suggested to an undergraduate student that they change degree programs to Interdisciplinary Studies (IDS). Prior to the Fall 2019 implementation of the (BGS) degree, the IDS Bachelor of Science and Bachelor of Arts degree programs were the primary option for students with a range of majors, accumulated credits, and diverse curricular interests. While the IDS degree required students to fulfill requirements in two disciplinary 
areas of study and a minor, the BGS degree program was introduced to provide students greater flexibility with coursework. It was important to know whether one of the two groups, faculty and staff, were more likely to have suggested to an undergraduate that they change their degree to IDS. In order to determine this, the odds of one group as opposed to the other were computed using a 2 x 2 contingency table with Faculty and Academic Advisors, plus Yes or No. The odds were calculated using a .95 confidence interval. The results showed that of the individuals who completed the survey, academic advisors were 27 times more likely to refer a student to IDS than a faculty member. The differences between the two groups was statistically significant with $\mathrm{p}=.05$.

The same approach was taken for the second question. Results showed that Academic Advisors were 23 times more likely to have heard about the BGS degree program as faculty.

The third question provided the mission of the BGS degree program and then asked participants how likely it would be that they would suggest to an undergraduate student that they change degree programs to BGS. The nonparametric test, Mann-Whitney U test, was selected to use within the SPSS statistical analysis program in order to compare differences between the faculty and academic responses. The assumptions for this analysis required that the dependent variable was measured as ordinal, which it was: the four-point scale for responses met that assumption. The second assumption met was that the independent variable consisted of two independent groups, faculty and academic advisors. The third assumption met was that an independence of observations existed, or that faculty and academic advisors were each in their own group, and there was no overlap. The last assumption was that the distributions had the same shape, which is an assumption that could not be determined in this study and the reason why the $\mathrm{M}_{\text {rank }}$ or mean rank was used. The Mann-Whitney U test results indicated a statistically significant difference in responses to question three: faculty tended to be less likely $\left(\mathrm{M}_{\text {rank }}=73.11\right)$ than staff $\left(\mathrm{M}_{\text {rank }}=111.17\right), \mathrm{U}=1116.50, \mathrm{~N}=161, \mathrm{p}=.000$, to suggest to undergraduates that they change degree programs to BGS.

There were no statistically significant differences between faculty and staff advisors on a number of other survey items. Question 4 asked participants to indicate how true or not true a set of statements were for them. The same assumptions were met as in Question 3, so the results for Question 4 were also analyzed using the Mann-Whitney U test and the mean rank. The results indicated no statistically significant difference in levels of agreement for the statement "Not everyone admitted to my degree program will be able to graduate from it" between faculty $\left(\mathrm{M}_{\text {rank }}=78.18\right)$ and academic advisors $\left(\mathrm{M}_{\text {rank }}=87.22\right)$, Mann-Whitney $\mathrm{U}=1,801.00, \mathrm{~N}=159, \mathrm{p}=.292$.

There were also no differences in levels of agreement between faculty and advisors in the statements "Narrowly focused undergraduate disciplinary degree programs are more rigorous than programs with a broader focus" between faculty $\left(\mathrm{M}_{\text {rank }}=79.94\right)$, and academic advisors $\left(\mathrm{M}_{\text {rank }}=82.75\right)$, Mann Whitney $\mathrm{U}=1,976.00, \mathrm{~N}=160, \mathrm{p}=.747$, or "Undergraduate students with more than 120 credit hours should be eligible to earn an undergraduate degree" between faculty $\left(M_{\text {rank }}=77.49\right)$ and academic advisors $\left(\mathrm{M}_{\text {rank }}=89.95\right)$, Mann-Whitney $\mathrm{U}=1,713.00, \mathrm{p}=.151$. While the difference test between the two groups was important in these, it is also important to note that for each of these statements, both faculty and academic advisors responded that they agreed undergraduate disciplinary programs are more rigorous than programs with a broader focus, with the majority of responses at slightly above "agree" for both faculty and closer to "strongly agree" for academic advisors. If an $\mathrm{M}_{\text {rank }}$ is 50 , the responses would be equally divided between "agree" and "disagree," and an $\mathrm{M}_{\text {rank }}$ of 75 would indicated an equal division between "agree" and "strongly agree." The faculty $\mathrm{M}_{\text {rank }}=79.94$ indicated agreement and academic advisors $\mathrm{M}_{\text {rank }}=82.75$ indicated an even stronger agreement that narrowly focused undergraduate disciplinary degree programs are perceived as more rigorous than programs with a broader focus. Faculty also agreed that undergraduate students with more than 120 credit hours should be eligible to earn an undergraduate degree with an $\mathrm{M}_{\text {rank }}=77.49$, and academic advisors agreed more strongly with $\mathrm{M}_{\text {rank }}=89.95$, although the difference was not statistically significant.

Question 5 asked faculty and academic advisors to approximate the percentage of current undergraduate students who have earned more than 120 credit hours. The Mann-Whitney U test showed no statistically significant difference between the faculty and advisors' knowledge about the percentage of students with 120 credit hours. There was no statistically significant difference between the Faculty $\left(\mathrm{M}_{\text {rank }}=71.57\right)$ and academic advisors $\left(\mathrm{M}_{\text {rank }}=82.39\right) \mathrm{U}=1,604.00, \mathrm{~N}=147, \mathrm{p}=.193$ knowledge about the percentage of the university's undergraduates with more than 120 credit hours. Of interest, however, is that $33.3 \%$ of academic advisors and $12.3 \%$ of faculty selected the correct percentage of current university undergraduates in Fall '18, which was between $11 \%$ and $13 \%$. The results are illustrated in Table 5.

Results for Question 6 indicated how strongly participants agreed or disagreed on whether each of 10 different issues are university priorities. This question examined the faculty and academic advisors' knowledge, perceptions, and beliefs about university priorities related to core performance-based funding metrics and Hofstede's (1984, 2011) dimensions of culture identified in the interview results. The results were evaluated as a whole, and also as two separate groups. The 
results are reported in Tables 6 and 7, with an asterisk (*) next to statistically significant results. Table 6 indicates the results for dimensions of culture represented by the data. In Table 7, the results for the Mann-Whitney U test indicated two areas with a statistically significant difference between the perceptions of faculty and academic advisors: The first is that faculty $\left(\mathrm{M}_{\text {rank }}=83.55\right)$ showed a statistically significantly difference from academic advisors $\left(\mathrm{M}_{\mathrm{rank}}=66.44\right)$ that it is a university priority to offer degree programs that prepare students to solve today's complex problems $(\mathrm{U}=2,526.50, \mathrm{p}=.028)$. The second is that academic advisors $\left(\mathrm{M}_{\text {rank }}=95.20\right)$ were significantly more in agreement than faculty $\left(\mathrm{M}_{\text {rank }}=75.36\right)$, that FTIC graduation rates are a priority $(\mathrm{U}=1,544.50, \mathrm{p}=.015)$. The remaining survey questions provided data about the number of course faculty were teaching during the semester the survey was administered, and whether respondents had full-time or part-time status.

\subsubsection{Summary}

The results of the survey provided the answers to RQ2 - RQ5:

RQ2. Are faculty or academic advisors who advise students more likely to suggest to an undergraduate student that they change degree programs to Interdisciplinary Studies?

Answer: Of the faculty and academic advisors who completed the survey, academic advisors were 27 times more likely to refer a student to IDS than faculty, with $\mathrm{p}=.05$.

RQ3. Are faculty or academic advisors more likely to have heard about the BGS degree?

Answer: Academic advisors were 23 times more likely to have heard about the BGS degree program than faculty, with $\mathrm{p}=.05$.

RQ4. What is the likelihood that faculty or academic advisors will suggest to an undergraduate that they change degree programs to BGS?

Answer: Faculty were less likely than academic advisors to suggest to undergraduates that they change degree programs to BGS $\left(\mathrm{M}_{\mathrm{rank}}=73.11\right)$ than staff $\left(\mathrm{M}_{\mathrm{rank}}=111.17\right)$.

RQ5. Does the organizational culture of the undergraduate faculty and academic advisors surveyed differ from that of the university administrators and faculty member interviewed?

Answer: The dimensions of culture matched, with the exception of power distance (Hofstede, 1984). In this dimension, survey results from faculty and academic advisors were slightly more likely to favor a higher power distance and more faculty-oriented culture than a lower one. The interview results from faculty and administrators emphasized a lower power distance and more student-oriented culture. This is an important and valuable point representative of cultural differences that exist between the administrators interviewed in the first part of the study and the faculty and advisors surveyed in the second part. These differences will factor in to the strategic internal communication developed for the BGS degree program.

\section{Discussion}

The dimensions of culture discussed in the interviews results of Study 1 were confirmed by the survey results. A collectivist or community-oriented dimension was indicated with $77 \%$ of faculty and $78.7 \%$ of academic advisors in agreement that a sense of community in degree programs was a university priority. Also identified was the professionalism dimension of culture, one that emphasized collaborative efforts between degree programs was a priority at the university with academic advisors $(81.8 \%)$ in higher agreement than faculty $(69.7 \%)$. Power distance was determined to be almost equally divided between high and low power, with faculty (55.9\%) learning slightly more to high power distance than academic advisors (54.6\%). Survey results indicated a more pragmatic culture than normative one, with faculty $(76.2 \%)$ and academic advisors $(78.8 \%)$, in agreement that academic pathways that increase completion rates is a university priority (Hofstede et al., 1990). Lastly, the survey results indicated a results-oriented organizational culture among the undergraduate advising faculty and academic advisors who responded to whether time to degree for all students of 4 to 6 years was a priority at the university (Hofstede et al., 1990). These results provided the cultural context within which strategic internal communication will serve as a type of teaching and learning relationship with undergraduate faculty and academic advisors involved with advising undergraduate students.

Hofstede's (1998) research into cross-organizational differences identified cultural differences in practices for participants from different organizations within the same country, and cultural differences in values for participants from different countries. The term "Practices" is relative to the symbolic frame within organizational theory, and is defined as "the symbols, heroes, and rituals specific to one culture as opposed to others; they are the visible part of cultures, while values represent the invisible part" (p. 482). Bolman and Deal (2013) identified symbols within the context of a mental model, as "a set of ideas and assumptions that you carry in your head to help you understand and negotiate a particular territory" (p. 10). Symbols are classified as shallow, and values as deep. Practices included parochial vs. professional, process-oriented vs. 
results-oriented, and pragmatic vs. normative. Values included individualism vs. collectivism and power distance (Hofstede, 1984, 2011).

To connect with faculty and academic advisors on the value of the BGS degree program, a localized communication strategy grounded in the key elements of the university's culture will deliver the message about the value of BGS. The survey indicated that strategic internal communication should be written with an emphasis on the cultural dimensions of collectivism (community), professionalism (cooperation and trust), balanced power-distance (lower power distance of student-centered learning balanced with the higher power distance of the expertise and authority of the faculty and university), pragmatism (practical results are more important than procedures, as is a blunt pragmatic communication style), and a results-oriented organizational culture with less bureaucracy and more concern for outcomes and the flexibility to adapt to student needs.

\section{Strategic internal communication}

The role that culture and social relationships play in promoting cognitive change or learning has been closely associated with Vygotsky's (1978) sociocultural theory (SCT). His work has applications to learning as it relates to promoting cognitive change in an organizational culture. Vygotsky's analysis of the ways that individuals create and assign meaning in their social interactions through the use of language demonstrates that "as learning environments change, the available mediational tools and signs that can impact cognitive functioning also change" (Bonk \& Kim, 1998, p. 69). If organizational communication can be viewed as a type of instruction or teaching relationship, then undergraduate faculty and academic advisors can learn what is happening with undergraduates in general, and with the BGS program, specifically. One tool useful for this is a targeted list of undergraduate faculty and academic advisors that is regularly updated. This list will be an important tool used by BGS advisors to communicate with and regularly survey undergraduate faculty and academic advisors about issues affecting undergraduate education. This communication would act as a mediational tool used at regular intervals for strategic internal communication and an exchange of information. If the goal is cognitive change about the value of a generalist vs. narrowly disciplinary degree program, then it is first necessary to understand the undergraduate advising sociocultural context, an understanding that can be negotiated and learned by both the faculty and academic advisors and the BGS advisors and program.

Communication in an organization with divisionalized semi-autonomous units (Bolman \& Deal, 2013) such as the university, should be distributed to the extent that it will help to achieve the stated goals of increasing the awareness and value of the BGS degree program (Austin \& Pinkelton, 2001). This type of communication can be regarded as a two-way symmetrical model that promotes mutual benefits and resolves conflict.

Gruning and Hunt's (1984) two-way symmetrical model provides a theoretical framework grounded in systems theory and identifies organizations as either open or closed systems. In the open systems model, Gruning \& Hunt and Broom \& Dozier $(1984 ; 1990)$ posited that organizations interact with, impact, and are impacted by their environment. In order to avoid threats to their survival, organizations must:

Exchange information, energy, and material with their environments. Organizations operating in closed systems exist in a vacuum without interacting with or exchanging things with any organization or person... organizations that close themselves off from this exchange process become inert or disintegrate. In other words, they become irrelevant or ineffective (Austin \& Pinkelton, 2001, pp. 270-271).

If the university is viewed as a closed system, it is relevant to the types of information that will be shared or not shared about the BGS degree program within the separate, semi-autonomous units of the university. The survey results that indicated a lack of faculty and academic advisors' knowledge about the number of students with 120 credit hours was representative of a more closed than open system as it relates to the exchange of information. Only $12 \%$ of faculty and $33 \%$ of academic advisors knew that between $11-13 \%$ of undergraduates at the university had 120 credit hours or more. This data supports the claim that the university is operating as a closed system.

The survey results also indicated a statistically significant difference between faculty and academic advisor responses in knowledge about performance metrics related to university funding. For example, survey results showed that the difference between academic advisors and faculty in whether the university prioritizes graduation rate for FTIC students was statistically significant, with academic advisors tending to prioritize it more than faculty. This may indicate that academic advisors, not faculty, have, or value the knowledge that the FTIC graduation rates are one of ten key metrics used by the Florida Board of Governors' Performance-based Funding Model to determine university funding (2019a, 2019b). The FTIC designation is based on the enrollment data collected at time of an FTIC's first semester of enrollment after high school graduation, and includes the student's initial degree program and major. This information may not appear to be relevant or useful to faculty, unless they are also allowed to understand how this metric impacts their program and department's funding. It will be helpful 
to communicate to undergraduate faculty who advise students that FTIC students who declare into a program, but do not qualify to graduate from it, can be referred to the BGS degree as a pathway to complete their bachelor's degree, and that this will benefit the initial program completion rate. This is the type of open exchange process that has the ability to increase the awareness and value of the BGS degree program, and the focus of the type of sociocultural learning that strategic internal communication hopes to achieve. An open information exchange would provide important context in strategic internal communication.

Co-orientation theory (McLeod \& Chaffee, 1972; Newcomb, 1953) operates under the assumption that individuals interact with each other based on the way they understand each other's views and intentions---the way they are co-oriented toward an issue and toward each other. "It detects perceptions about an issue among organizational members as well as among organizational insiders and outsiders and investigates their in-between relationships, such as their levels of actual agreement and perceived agreement" (Goutzamani, 2016). Co-orientation theory takes into account the perception of stakeholder agreement as compared to actual stakeholder agreement, and holds that it is the perceptions that affect behavior more than the actual agreement itself (Scheff, 1967). Co-orientation is relevant to strategic internal communication in the way two groups (for example, faculty and academic advisors) are oriented toward an object such as the BGS degree, as well as the way those two groups are oriented toward each other (McLeod \& Chaffee, 1972). It is a useful way to understand stakeholders in that it requires common variables and functions based on common ground and mutuality. Strategic internal communication based on co-orientation will create content and communicate it in a two-way transaction that is based on trust, control mutuality (how much control the parties believe they have over the goals), relational commitment (faculty and program's ability to commit to being all in), and relational satisfaction (Stafford \& Canary, 1991).

An important element of putting the co-orientation theory into practice with undergraduate faculty and academic advisors will be communicating "why" they should share the university's view on the importance of BGS to students and the university as a whole. Building on the example of FTIC graduation rates and "why" this metric relates to both the administrative and faculty sides of the university, are the variables of student success and university funding. The survey results showed that faculty (12\%) and academic advisors (33\%) believed a much smaller percentage of students had 120 credit hours than the actual number. The results also indicated that the difference between the faculty and academic advisors' perception of the university priority of FTIC graduation rates was statistically significant, with academic advisors $\left(\mathrm{M}_{\text {rank }}=95.20\right)$ being better informed that FTIC graduation rates are a priority at the university than faculty $\left(\mathrm{M}_{\text {rank }}=75.36\right)$. Regular communication between the BGS director of advising and undergraduate faculty and academic advisors about issues affecting undergraduate education will be an important part of strategic internal communication.

Co-orientation and its application in communication efforts could promote the long-term success of the BGS degree program (Grunig \& Huang, 2001). Ultimately, success will be based on how well the university integrates the needs of its many semi-autonomous units into its own organizational goals in a way that co-orients the units as opposed to dividing them with faculty on one side and the upper administration on the other, each with different goals. As part of a comprehensive and coordinated communication plan, the BGS program can conduct ongoing surveys targeted at the undergraduate faculty and academic advisors as a way to stay up-to-date with issues affecting undergraduate students and their education.

Strategic internal communication contextualized with the professionalism dimension of culture should emphasize that collaborative efforts between degree programs is a priority of the university. Information about academic pathways that increase access to students and completion rates also connect to the cultural dimension of pragmatism. Combining the collaborative efforts between degree programs and the new pathways to graduation provided by the BGS program (and the leadership and project management skills the program teaches) can provide an additional framework for faculty and academic advisors, and contribute to the sociocultural learning to facilitate common ground and an understanding of why BGS matters to them. This type of social constructivism helps develop meaning in the way that BGS information is communicated, and the context in which it is received and understood. Through this type of strategic communication, undergraduate faculty and academic advisors will develop an understanding that students in BGS use their prior coursework and previous degree program experiences to develop and manage a summative project connected to all of the academic and professional interests developed during their time at the university.

A key point to address is the survey result that faculty tended to be less likely than academic advisors to suggest to undergraduates that they change degree programs to BGS. If the cognitive framework faculty use is for disciplinary degree programs, then strategic communication should reframe BGS as a degree program designed to fit the highly integrative world outside of the university. The survey results indicated that $88 \%$ of faculty and $85 \%$ of academic advisors agreed that integrative learning opportunities for students were a priority at the university. Survey results also indicated that $70 \%$ of faculty and $82 \%$ of academic advisors agreed that collaborative efforts between degree programs were also a priority. This 
data provides a framework for common ground to build on for strategic internal communication that details the many ways that BGS is a collaborative degree program, one that increases opportunity for all involved.

\section{Summary}

In summary, the localization strategy most useful for communicating information about the BGS degree program and how its implementation supports university priorities will focus on the cultural dimensions of collectivism (community), professionalism (cooperation and trust), balanced power-distance (lower power distance of student-centered learning balanced with the higher power distance of the expertise and authority of the faculty and university), pragmatism (practical results are more important than procedures, as is a blunt pragmatic communication style), and having a results-oriented organizational culture (fewer bureaucratic routines and greater concern for outcomes, and willingness to adapt to needs).

The BGS advisors and degree program administrators can keep an updated targeted list of undergraduate faculty and academic advisors to use as a tool to communicate with undergraduate faculty and academic advisors to facilitate learning and discussion about issues affecting undergraduate students, and the BGS degree. In doing this, content should focus on how BGS fits within the goals of the many semi-autonomous departments at the university, and within its larger organizational goals. This co-orientation involves the way that undergraduate faculty, academic advisors, and the university view and understand the BGS degree program in relation to their own needs and goals. Additional research into the needs of the different semi-autonomous units and how these fit within the university's goals could help direct these efforts to further identify common ground and conflicts, and facilitate learning about the value of the BGS degree.

\section{Declaration}

This is to acknowledge that there is no financial interest or benefit to the authors that has arisen from the direct applications of this research.

This article is an analysis and elaboration of the 2 studies presented here. They were part of the primary author's original doctoral dissertation research and have not been previously published in any scholarly outlet.

\section{References}

[1] Allen, E., \& Seaman, C. Likert scales and data analyses. Quality Progress. 2007; 40(7): 64-65.

[2] Austin, E. W., \& Pinkelton, B. E. Strategic public relations management: Planning and managing effective communications programs. Mahwah, NJ: Laurence Erlbaum Associates; 2001.

[3] Bolman, L.G., \& Deal, T. E. Reframing organizations: Artistry, choice, and leadership. 5th ed. San Francisco, CA: Jossey-Bass; 2013.

[4] Bonk, C. J., \& Kim, K. A. Extending sociocultural theory to adult learning. In M. C. Smith \& T. Pourchot. (Eds.) Adult Learning and Development: Perspectives from Educational Psychology (pp.67-88). N.J.: Lawrence Erlbaum; 1998.

[5] Braun, V., \& Clarke, V. Using thematic analysis in psychology. Qualitative Research in Psychology. 2006; 3(2): 77-101.

[6] Broom, G. M., \& Dozier, D. M. Using research in public relations: Applications to program management. Englewood Cliffs, NJ: Prentice-Hall; 1990.

[7] Chen, H. T. Theory-driven evaluations. Newbury Park, CA: Sage Publications; 1990.

[8] Creswell, J. W. Educational research: Planning, conducting, and evaluating quantitative and qualitative research. $3 \mathrm{rd}$ ed. Upper Saddle River, NJ: Pearson Education; 2008.

[9] Damen, L. Culture learning: The fifth dimension of the language classroom. Reading, MA: Addison-Wesley; 1987.

[10] Deal, T. E., \& Kennedy, A. A. Corporate cultures: The rites and rituals of corporate life. Reading, MA: Addison-Wesley; 1982.

[11] Florida Board of Governors. (2019a). Performance-based funding study: an updated performance-based funding model. Available from: https://www.flbog.edu/wp-content/uploads/PBF-Study-An-Updated-Performance-Based-FundingModel-Dec-2019.pdf

[12] Florida Board of Governors. (2019b). Board of governors' performance-based funding model (10 metrics) questions and answers. Available from: https://https://www.flbog.edu/wp-content/uploads/PBF-FAQs-10_metric_model-June2019. pdf

[13] Goutzamani, E. Co-Orientation theory. In: C. E. Carroll. (Ed.) The SAGE encyclopedia of corporate reputation (pp. 160-162). Thousand Oaks, CA: Sage Publications; 2016.

[14] Grunig, J. E., \& Repper, F. C. Managing public relations. New York: Holt, Rinehart \& Winston; 1992. 
[15] Grunig, J., Dozier, D. \& Grunig, J. Excellent Public Relations and Effective Organizations. New York: Routledge; 2002. Available from: https://doi.org/10.4324/9781410606617

[16] Guest, G., MacQueen, K., \& Namey, E. Applied thematic analysis. Thousand Oaks, CA: Sage Publications; 2012.

[17] Higher Education Research Institute (HERI). (2016-2017). Faculty survey instrument. University of California at Los Angeles. Available from: https://www.heri.ucla.edu/PDFs/surveyAdmin/fac/INSTRUMENT/2016FAC.pdf

[18] Hofstede, G. Culture's consequences: International differences in work-related values. Thousand Oaks, CA: Sage Publications; 1984.

[19] Hofstede, G. Attitudes, values and organizational culture: Disentangling theconcepts. Organization Studies. 1998; 19(3): 477-493. Available from: https://doi.org/10.1177/017084069801900305

[20] Hofstede, G. Dimensionalizing cultures: The Hofstede model in context. Online Readings in Psychology and Culture. 2011; 2(1). Available from: https://doi.org/10.9707/2307-0919.1014

[21] Hofstede, G., Neuijen, B., Ohayv, D. D., \& Sanders, G. Measuring organizational cultures: A qualitative and quantitative study across twenty cases. Administrative Science Quarterly. 1990; 35(2): 286-316. Available from: https://doi. org/10.2307/2393392

[22] McLeod, J. M., \& Chaffee, S. H. The construction of social reality. In: J. Tedeschi. (Ed.) The social influence process (pp. 50-59). Chicago, IL: Aldine-Atherton; 1972.

[23] Newcomb, T. An approach to the study of communicative acts. Psychological Review. 1953; 60: 393-404.

[24] Repko, A. F., \& Szostak, R. Interdisciplinary research: process and theory. 3rd ed. Los Angeles, CA: Sage Publications; 2017.

[25] Rhee, Y., \& Moon, B. Organizational culture and strategic communication practice: Testing the competing values model (CVM) and employee communication strategies (ECS) model in Korea. International Journal of Strategic Communication. 2009; 3(1): 52-67. Available from: https://doi.org/10.1080/15531180802608386

[26] Scheff, T. J. Towards a sociological model of consensus. American Sociological Review. 1967; 32(1): 32-46. Available from: https://doi.org/10.2307/2091716

[27] Smircich, L. Concept of culture and organizational analysis. Administrative Science Quarterly. 1983; 28(3): 339-358.

[28] Smidts, A, Pruyn, A., \& van Riel. The impact of employee communication and perceived external prestige on organizational identification. Academy of Management Journal. 2001; 44(5): 1051-1062.

[29] Sriramesh, K., Grunig, J. E., \& and Buffington, J. Corporate culture and public relations. In: J. E. Grunig. (Ed.) Excellence in public relations and communication management (pp. 577-596). Hillsdale, NJ: Lawrence Erlbaum Associates; 1992.

[30] State University System of Florida. (2019). 2025 strategic plan for the State University System of Florida. Florida Board of Governors. Available from: https://www.flbog.edu/wp-content/uploads/2019-Review-of-Metrics-1.pdf

[31] Szostak, R. Classifying science: Phenomena, data, theory, method, practice. Dordrecht, The Netherlands: Springer; 2004.

[32] Vygotsky, L. S. Mind in society: The development of higher psychological processes. Cambridge, MA: Harvard University Press; 1978. 


\section{Appendix}

Table 1. Findings: Formulated meanings from significant statements

\begin{tabular}{|c|c|}
\hline Significant Statements & Formulated Meanings \\
\hline $\begin{array}{l}\text { It does not mean they don't value higher education. It } \\
\text { means they do value it. }\end{array}$ & Students value higher education to earn a degree. \\
\hline For those students we do not have a good solution. & The university lacks a general education degree program. \\
\hline
\end{tabular}

Table 2. Findings: Emergent themes for the BGS degree

\begin{tabular}{ccc}
\hline Formulated Meanings & Theme Cluster & Emergent Theme \\
\hline $\begin{array}{c}\text { Students value higher education to } \\
\text { earn a degree. }\end{array}$ & $\begin{array}{c}\text { Students may have accumulated more } \\
\text { academic experience and knowledge than } \\
\text { many of their degreed counterparts. }\end{array}$ & Student motivation and outcomes. \\
$\begin{array}{c}\text { A general education degree is offered at } \\
\text { many universities worldwide, yet there } \\
\text { education degree. }\end{array}$ & $\begin{array}{c}\text { University motivation and outcomes for a } \\
\text { gurrently is not one at our university. }\end{array}$ & $\begin{array}{c}\text { geducation degree and how it fits within } \\
\text { the culture of the university. }\end{array}$ \\
\hline
\end{tabular}

Table 3. Survey question 1

\begin{tabular}{ccccc}
\hline & Yes & No & Totals & Odds Ratio \\
\hline Academic & 29 & 4 & 33 & 27 \\
Advisors & 27 & 101 & 128 & \\
Faculty & 128 & 33 & 161 & \\
Total & 128 &
\end{tabular}

Table 4. Survey question 2

\begin{tabular}{ccccc}
\hline & Yes & No & Totals & Odds Ratio \\
\hline Academic Advisors & 30 & 3 & 33 & 23 \\
Faculty & 38 & 89 & 123 & \\
Total & 68 & 92 & 156 & \\
\hline $\mathrm{p}=.05$ & & &
\end{tabular}

Table 5. Survey question 5

\begin{tabular}{cccc}
\hline & Answer & Academic Advisors & Faculty \\
\hline 1 & $<0.1 \%$ & 0 & $3.5 \%$ \\
2 & Between .1 to 1\% & $3 \%$ & $4.4 \%$ \\
3 & Between 1\% and 3\% & $15.2 \%$ & $14 \%$ \\
4 & Between 3\% and 5\% & $9.1 \%$ & $15.8 \%$ \\
5 & Between 5\% and 7\% & $24.2 \%$ & $17.5 \%$ \\
6 & Between 7\% and 9\% & $12.1 \%$ & $10.5 \%$ \\
7 & Between 9\% and 11\% & $3 \%$ & $21.9 \%$ \\
8 & Between 11\% and 13\% & $33.3 \%$ & $12.3 \%$ \\
& Total & $100 \%$ & $100 \%$ \\
\hline
\end{tabular}


Table 6. Survey question 6: Dimensions of culture

Issues you believe are currently a priority at the university. Select from Strongly Agree to Strongly Disagree in response to your belief about the priority of each issue at the university.

\begin{tabular}{|c|c|c|c|c|c|c|c|}
\hline $\begin{array}{c}\text { Question: } \\
\text { University priority }\end{array}$ & $\begin{array}{l}\text { Dimension of } \\
\text { Culture }\end{array}$ & Faculty $\mathrm{M}_{\text {rank }}$ & $\begin{array}{l}\% \text { Faculty } \\
\text { Agree }\end{array}$ & $\begin{array}{c}\text { Academic } \\
\text { Advisor } \mathrm{M}_{\mathrm{rank}}\end{array}$ & $\begin{array}{c}\% \text { Academic } \\
\text { Advisors Agree }\end{array}$ & U Value & $\mathrm{p}$ value \\
\hline $\begin{array}{l}\text { A sense of community } \\
\text { in degree programs. }\end{array}$ & $\begin{array}{l}\text { Individualism vs } \\
\text { Collectivism }\end{array}$ & $\mathrm{M}_{\mathrm{rank}}=79.69$ & 77 & $\mathrm{M}_{\mathrm{rank}}=81.20$ & 78.7 & $\mathrm{U}=2,039.50$ & $\mathrm{p}=.853$ \\
\hline $\begin{array}{l}\text { Collaborative efforts } \\
\text { between degree } \\
\text { programs. }\end{array}$ & $\begin{array}{c}\text { Parochial } \\
\text { vs Professional }\end{array}$ & $\mathrm{M}_{\text {rank }}=77.13$ & 69.7 & $\mathrm{M}_{\mathrm{rank}}=90.95$ & 81.8 & $\mathrm{U}=1,717.50$ & $\mathrm{p}=.099$ \\
\hline $\begin{array}{l}\text { Maintaining the } \\
\text { traditional disciplinary } \\
\text { degree structures. }\end{array}$ & $\begin{array}{l}\text { Power } \\
\text { Distance }\end{array}$ & $\mathrm{M}_{\mathrm{rank}}=79.28$ & 55.9 & $\mathrm{M}_{\mathrm{rank}}=77.94$ & 54.6 & $\mathrm{U}=2,081$ & $\mathrm{p}=.869$ \\
\hline $\begin{array}{l}\text { Academic pathways } \\
\text { that increase completion } \\
\text { rates. }\end{array}$ & $\begin{array}{l}\text { Pragmatic } \\
\text { vs } \\
\text { Normative }\end{array}$ & $\mathrm{M}_{\text {rank }}=78.04$ & 76.2 & $\mathrm{M}_{\mathrm{rank}}=87.50$ & 78.8 & $\mathrm{U}=1,831.5$ & $\mathrm{p}=.258$ \\
\hline $\begin{array}{l}\text { Time to degree for all } \\
\text { students of } 4 \text { to } 6 \text { years. }\end{array}$ & $\begin{array}{c}\text { Process-Oriented } \\
\text { vs } \\
\text { Results-Oriented }\end{array}$ & $\mathrm{M}_{\mathrm{rank}}=79.92$ & 84.4 & $\left(\mathrm{M}_{\mathrm{rank}}=80.30\right.$ & 87.9 & $\mathrm{U}=2,069$ &,$p=.963$ \\
\hline
\end{tabular}

$$
\mathrm{N}=160, \mathrm{p}=.05
$$

Table 7. University collective impact core metrics

\begin{tabular}{|c|c|c|c|c|c|c|c|}
\hline $\begin{array}{c}\text { Question: } \\
\text { University priority }\end{array}$ & $\begin{array}{l}\text { Collective Impact } \\
\text { Knowledge }\end{array}$ & Faculty $\mathrm{M}_{\mathrm{rank}}$ & $\begin{array}{l}\% \text { Faculty } \\
\text { Agree }\end{array}$ & $\begin{array}{c}\text { Academic } \\
\text { Advisor } \mathrm{M}_{\mathrm{rank}}\end{array}$ & $\begin{array}{l}\% \text { Academic } \\
\text { Advisors Agree }\end{array}$ & U Value & $\mathrm{p}$ value \\
\hline $\begin{array}{l}\text { Graduation rates for } \\
\text { transfer students from } \\
\text { Direct Connect or other } \\
\text { institutions. }\end{array}$ & Collective Impact & $\mathrm{M}_{\mathrm{rank}}=76.95$ & 83.5 & $\mathrm{M}_{\mathrm{rank}}=87.00$ & 87.5 & $\mathrm{U}=1,744.00$ & $\mathrm{p}=.210$ \\
\hline $\begin{array}{l}\text { Graduation rates for } \\
\text { non-traditional students. }\end{array}$ & & $\mathrm{M}_{\mathrm{rank}}=78.22$ & 79.4 & $\mathrm{M}_{\text {rank }}=84.33$ & 81.8 & $\mathrm{U}=1,903.00$ & $\mathrm{p}=.451$ \\
\hline $\begin{array}{c}\text { * Graduation rates } \\
\text { for FTIC (First Time } \\
\text { in College) students } \\
\text { who start immediately } \\
\text { following high school } \\
\text { graduation. }\end{array}$ & & $\mathrm{M}_{\mathrm{rank}}=75.36$ & 86.8 & $\mathrm{M}_{\text {rank }}=95.20$ & 93.9 & $\mathrm{U}=1,544.50$ & $\mathrm{p}=.015$ \\
\hline $\begin{array}{l}\text { * Degree programs } \\
\text { that prepare students to } \\
\text { solve today's complex } \\
\text { problems. }\end{array}$ & & $\mathrm{M}_{\text {rank }}=83.55$ & 95.9 & $\mathrm{M}_{\text {rank }}=66.44$ & 84.9 & $\mathrm{U}=2,526.50$ & $\mathrm{p}=.028$ \\
\hline $\begin{array}{l}\text { Integrative learning } \\
\text { opportunities for } \\
\text { students. }\end{array}$ & & $\mathrm{M}_{\text {rank }}=78.37$ & 87.6 & $\mathrm{M}_{\text {rank }}=83.79$ & 84.9 & $\mathrm{U}=1,921.00$ & $\mathrm{p}=.506$ \\
\hline
\end{tabular}

$\mathrm{N}=160, \mathrm{p}=.05$ 